DOI 10.37882/2223-2982.2021.07.13

\title{
ОРГАНИЗАЦИЯ ВОСПИТАТЕЛЬНОЙ РАБОТЫ С ДЕТЬМИ «ГРУППЫ РИСКА» В ЗАГОРОДНОМ ОЗДОРОВИТЕЛЬНОМ УЧРЕЖДЕНИИ: ИЗ ОПЫТА РАБОТЫ
}

\section{ORGANIZATION OF EDUCATIONAL WORK WITH CHILDREN OF THE "RISK GROUP" IN A COUNTRY HEALTH INSTITUTION: FROM WORK EXPERIENCE}

\section{K. Kamenev}

N. Sablina

Summary: The article examines and analyzes the pedagogical work with children of the "risk group" in the conditions of suburban healthimproving institutions in Belgorod. The basic principles of the formation of children's groups are considered. The main problems inherent in each of the forms of selecting a children's team and organizing pedagogical work are identified. The necessity of purposeful work on the formation of a culture of communication and labor education of children in the summer health camp is justified. The main interested structures for the prevention of offenses in the adolescent environment are identified. The ways of increasing the effectiveness of this pedagogical work are outlined.

Keywords: educational work in a country camp, prevention of offenses, formation of a culture of interpersonal communication, labor education, children of the "risk group".
В организации воспитательной работы с детьми можно выделить два периода: первый - учебный год, когда дети большую часть времени находятся в школе, и второй - каникулярное время. В связи с объективными обстоятельствами, во время каникул, контроль за детьми снижается. Дети большую часть времени предоставлены сами себе. Как результат - резкий всплеск подростковой преступности, несчастных случаев, участие подростков в ДТП, повышение смертности среди подростков.

Одной из форм организации работы с детьми в каникулярное время является проведение профильных смен на базе загородных оздоровительных лагерей. В силу значительных отличий этой формы работы с детьми следует заметить ее особую роль в воспитании, организации занятости, профилактике правонарушений среди несовершеннолетних детей, относящихся к категории «группа риска».

Особенности данной формы работы с детьми состоят в следующем:

\author{
Каменев Константин Владимирович \\ Директор, МБУ ДОЛ «Электроника» г. Белгорода \\ 89606400000@mail.ru \\ Саблина Наталья Михайловна \\ Главный специалист, отдел дополнительного \\ образования и занятости детей управления образования \\ администрации г. Белгорода
}

Аннотация: В статье раскрываются особенности воспитательной работы с детьми «группы риска» в условиях загородных оздоровительных учреждений. Рассматриваются основные принципы формирования детских коллективов. Актуализированы основные проблемы детского коллектива и организации педагогической работы. Обоснована необходимость целенаправленной работы по формированию культуры общения и трудовому воспитанию детей в летнем оздоровительном лагере. Раскрыта роль социальных партнеров в работе по профилактике правонарушений в подростковой среде. Намечены пути повышения эффективности данной педагогической работы.

Ключевые слова: воспитательная работа в загородном лагере, профилактика правонарушений, формирование культуры межличностного общения, трудовое воспитание, дети «группы риска».

1. значительно расширяется пространство, в котором подростки могут развивать свою активность, демонстрировать те качества, которые часто остаются не раскрытыми в школе, в семье, среди сверстников;

2. успешнее решаются проблемы социальной адаптации подростков, формируется культура межличностного общения, культура пространства свободного времени, здорового образа жизни;

3. использование игровых форм воспитания, плотность, интенсивность и насыщенность взаимодействия педагога с ребёнком. Это происходит изза, фактически, круглосуточного взаимодействия педагога и ребенка при решении различных бытовых проблем, при выполнении досуговой программы учреждения.

4. отличие от школьного взаимодействия педагога и ребенка в лагере проявляется в большей значимости для ребенка умения строить социальные отношения. Если в школе более важны информационные отношения, такие как: знания, эрудиция, точность выполнения заданий, то в лагере на пер- 
вый план выходит способность строить социальные отношения. При этом важны коммуникабельность, практичность, мобильность, самоуважение и прочее. Эти особенности проявляются во время игр, совместных дел, конфликтов, примирений, во время круглосуточного проживания со своими сверстниками.

В лагере ребёнок попадает в новый для него коллектив, что позволяет заново построить межличностные коммуникации. Таким образом, лагерь - это место, где педагогическое влияние может быть более интенсивным и эффективным.

Кроме того, в лагере у ребенка строятся качественно новые отношения со взрослыми. В школе между учителем и учеником далеко не всегда возникают товарищеские, союзнические отношения. В лагере же взрослый - вожатый, воспитатель устанавливает с ребёнком более короткую, доверительную дистанцию в силу небольшой разницы в возрасте и круглосуточного взаимодействия. Данный опыт общения со взрослыми разнообразного статуса и рода занятий необходим для нормальной социализации человека. В лагере взрослый не связан социальной ролью учителя, поэтому общение между взрослым и ребёнком приобретает более широкие границы.

Практика привлечения детей «группы риска» в организованную оздоровительную кампанию используется в воспитательной системе города Белгорода по двум направлениям.

Первое направление - это интеграция детей различных социальных групп, таких как дети из малоимущих семей, дети, находящиеся в трудной жизненной ситуации, дети с ограниченными возможностями здоровья, дети, состоящие на различных видах профилактического учета, дети из творческих и спортивных коллективов. Все они группируются в единую типовую лагерную смену.

Второе направление - это организация специализированных групп, когда дети категории «группы риска» привлекаются к оздоровлению в загородных лагерях по программе профильной смены. Традиционно эта смена, которая формируется детьми города Белгорода, называется «Данко», детьми Белгородской области называется «еникс».

Основная идея первого направления - интеграция детей разных социальных групп в единое сообщество, чтобы использовать воспитательное воздействие самого детского коллектива. Это позволяет участникам лагерной смены приобрести опыт жизни в гуманной, доброжелательной атмосфере, в атмосфере уважения, обеспечивает реабилитацию и адаптацию детей «группы риска». В этом случае делается ставка на воспитательную силу детского коллектива. Имеется в виду, что при наличии квалифицированного педагогического персонала в лагере, который умело сформирует детский коллектив, направит его развитие и влияние в нужное русло.

Особенностью педагогического коллектива в загородных лагерях является то, что в качестве воспитателей и вожатых работает много студентов, которые не имеют большого педагогического опыта работы с детьми и не знают личностных психологических особенностей конкретного ребенка. Поэтому часто, мы наблюдаем, обратный запланированному эффект. А именно, дети, которых планировали «перевоспитывать», становятся лидерами мнений, ориентирами для подражания. Дети «группы риска» чаще всего ведут себя в коллективе агрессивно и притесняют интересы других детей, парализуют работу детского коллектива. В этом случае в детском коллективе складывается не благоприятная атмосфера. Все это не способствует развитию коллектива детей в целом и каждого ребенка в отдельности. В этом случае дети часто покидают лагерь досрочно.

Как правило, большие сложности возникают у педагогического коллектива в связи с тем, что досуговая программа детского отдыха строится с ориентиром на ребенка без девиантных или делинквентных особенностей поведения. В результате дети не типичные «выпадают» из педагогического воздействия. Необходимость заниматься ими отдельно сталкивается с объективными трудностями. Как следствие, самым простым способом «разрубить Гордиев узел», это отправить такого ребенка домой. То есть ребенок возвращается на улицу со всеми вытекающими последствиями.

Штатное расписание лагерей не предусматривает должности психолога. Фактические попытки вожатых и воспитателей взаимодействия с детьми, имеющими отклоняющееся поведение, сталкивается с отсутствием соответствующих компетенций и банально времени на разработку и осуществление стратегии поведения с данным ребёнком.

Большая проблема связана и с негативом родителей детей, которые часто страдают от поведения детей «с особенностями». Далеко не все родители разделяют идею социализировать детей «группы риска» за счет своих детей.

При всех тонкостях и сложностях этой ситуации с точки зрения закона, принципов гуманности и прочее, эта проблема очень остра.

Вторым направлением работы с детьми данной категории является организация профильной смены. Как указывалось выше, эта смена называется «Данко» или 
«Феникс». При реализации специфической профильной смены для детей «группы риска», используется принцип межведомственного подхода. Смена организуется на базе одного из лагерей учредителями, которых является Управление Образования г. Белгорода. Финансирует данную работу Управление Социальной Защиты Белгородской области из Федеральных средств на оздоровление детей находящихся в трудной жизненной ситуации

Отличие специфической профильной смены «Данко» и «Феникс», для детей «группы риска» состоит в том, что на данной смене оздоравливаются дети только этой категории. В случае невозможности заполнить лагерь полностью детьми данной категории, оставшиеся места распределяются среди детей являющихся членами различных коллективов, в основном спортивных. Но эти дети находятся в отдельных отрядах и отдыхают эти коллективы по своей программе.

К работе с детьми «группы риска» привлекаются опытные социальные педагоги, курсанты старших курсов Белгородского юридического института и сотрудники ДОСААФ. Для усиления профилактики поведенческих нарушений в течение смены организовываются встречи со специалистами областного наркодиспансера, с сотрудниками Управления Федеральной службы по контролю за оборотом наркотиков, УМВД, МЧС, отряда милиции особого назначения. Привлекаются сотрудники управлений культуры, молодежной политики, физической культуры и спорта. На смене организована работа кружков по интересам художественной и спортивной направленности.

Традиционно общая тематика данной смены - военно-патриотическая. В этом случае решается сразу несколько вопросов: с одной стороны, это привлекает внимание детей, это необычно, это вызывает у них интерес. С другой стороны, военно-патриотическая специфика подразумевает определенную дисциплину и физическую нагрузку. В этом случае, больше внимания уделяется на коллектив детей в целом, а уже через коллектив осуществляется воздействие на каждого.

Работа представителей социальных партнеров способствует повышению правовых знаний несовершеннолетних, популяризации военно-прикладных видов спорта, воспитанию чувства патриотизма и гордости за свою Родину, для юношей - привлекательности службы в рядах вооруженных сил России и ведомствах силовой направленности.

В работе с детьми «группы социального риска» применяются разнообразные методы, такие как: вовлечение в деятельность, стимулирование, увлечение, доверие, сотрудничество и т.д., но наиболее эффективными методами показывают себя следующие:
- метод переубеждения заключается в предоставлении детям и подросткам убедительных аргументов принятия мотивации, заставляющих их критически оценивать свои поступки;

- метод переключения видов деятельности - чередование занятий, спортом, художественным творчеством, новой общественной деятельностью.

Перспективным в работе с детьми, а особенно с детьми данной категории, видеться трудовое воспитание. В настоящее время данная форма используется крайне редко, хотя имеет большой потенциал. Сейчас ушла практика трудовых лагерей, стройотрядов. Программы работы с детьми в лагерях больше направленны на развлечение. Часто набор мероприятий складывается из сиюминутных веяний, единственной целью которых является весёлое, не затратное со стороны ребенка времяпрепровождение. Трудовое воспитание ребенка в лагере не имеет четкой направленности. В большей степени оно носит стихийный характер. Неумение же трудиться, отсутствие трудовых навыков, в последующем приводит к неумению и нежеланию работать, а необходимость в средствах для жизни, для удовлетворения материальных потребностей толкает человека на криминальный путь.

На основе достаточного большого опыта работы автора данной статьи с детьми описываемой категории, можно сказать, что второе направление, а именно: проведение специализированной профильной смены для детей «группы риска» более рациональное, так как в этом случае более эффективно решаются задачи по профилактике правонарушений среди подростков. При организации профильных смен «Данко» проще составить программы адекватные индивидуальным особенностям и наклонностям детей данной категории. В этом случае возникает гораздо меньше конфликтов среди всех участников программы.

Исходя из опыта проведения выше описанных форм воспитательной работы с детьми можно сделать некоторые выводы, связанные с перспективами повышения эффективности работы с детьми «группы риска» в загородных лагерях, а именно:

- необходимо проведение специализированных смен для детей «группы риска»;

- целенаправленно заниматься формированием культуры межличностного общения;

- вводить в программу организации досуга детей элементы трудового воспитания;

- введение в штатное расписание лагерей единицы психолога для работы с детьми;

- развитие форм взаимодействия со всеми заинтересованными структурами по профилактике правонарушений в подростковой среде. 


\section{ЛИТЕРАТУРА}

1. Олевская И.А. Методика воспитания детского коллектива в опыте А.С. Макаренко как средства профилактики отклонений в поведении подростков / В.А. Николаев, Е.А. Гринева, Олевская И.А. // Социально-педагогический подход в образовании: воплощение наследия А.С. Макаренко в современных социальных проектах [Текст] : сборник научных трудов Всероссийской с международным участием конференции (Екатеринбург, 29 марта 2019 г.) / Урал. гос. пед. ун-т ; науч. ред. М.В. Богуславский, Т.С. Дорохова; — Екатеринбург: [6. и.], 2019. — 356 с.305-309. (5с.).

2. Олевская И.А. Правовая грамотность гражданского общества в условиях интеграции. Влияние средств массовой информации на правосознание // Экономические и правовые аспекты развития международной интеграции в современных условиях материалы Межрегиональной научно-практической конференции студентов, аспирантов и преподавателей. 2017. C.8-13. https:// elibrary.ru /item.asp?id=30529526

3. Олевская И.А. Воспитание детского коллектива в опыте А.С Макаренко как средства профилактики отклонений // Социально-педагогический подход в образовании: воплощение наследия Николаев В.А., Олевская И.А., Гринева Е.А. А.С. Макаренко в современных социальных проектах [Текст]: сборник научных трудов Всероссийской с международным участием конференции (Екатеринбург, 29 марта 2019 г.) / Урал. гос. пед. ун-т; науч. ред. М.В. Богуславский, Т.С. Дорохова; — Екатеринбург : [б. и.], 2019. — 356 с. С. 305-309. (5 с.).

4. Олевская И.А. Проблема воспитания адекватной самооценки у школьника в современных образовательных условиях // Народный педагогический журнал http://narodjourna1-preemstvennost.ru/2018/12/15/vypusk-0901-2019-chitat/\#0901-2019/0901-2019. Выпуск 9(01) 2019. С. $491-495$ (5 с.). 16. 0левская И.А. Проблема информационно-культурного деструктивизма в современном обществе // Актуальные вопросы современной науки и образования материалы международной научно-практической конференции. Московский финансово-юридический университет МФЮА, Кировский филиал. 2017. C. 181-184. (4 c.). https://elibrary.ru/item.asp?id=29398178

5. Олевская И.А. Межнациональные семейные отношения в процессе интеграции в современных условиях /0левская И.А., Илюхина А.Р. // Экономические и правовые аспекты развития международной интеграции в современных условиях материалы Межрегиональной научно-практической конференции студентов, аспирантов и преподавателей. Московский областной филиал Московского финансово-юридического университета МФЮА. 2017. С. 181-184. https://e1ibrary.ru/item.asp?id=30553027

6. Олевская И.А. Использование народных игр в коррекции отклоняющегося поведения детей /0левская И.А., Николаев В.А. Гринева Е.А.// Профессионализм педагога: сущность, содержание, перспективы развития: Материалы Международной научно-практической конференции посвященной 1 30-летию А.С. Макаренко 15-16 марта 2018 года г. Москва, МГОУ./ Под ред. Е.И. Артамоновой. В 2 ч. Часть 1. М.: МАНП0, 2018.408 c. https://elibrary.ru/ item.asp?id=35262424.C. $345-350$ (6 c.).

7. Е.С. Осокиной. Образовательная деятельность организаций отдыха детей и их оздоровления и ее сопровождение сборник научных трудов под редакцией // Редакторы: Осокина Е.С. Тип: сборник статей isbn: 978-5-906968-17-3 - 2017. - СПб., 2017. - 258 с. 4.000 "Ниц Арт" удк: 371.21

8. Агеева А.Н. Нормативно-правовая база социальной работы с детьми, находящимися в трудной жизненной ситуации. традиции и инновации в начальном образовании материалы региональной научно-практической конференции. // 2017 Елецкий государственный университет им. И.А. Бунина (Елец) Конференция: традиции и инновации в начальном образовании. Елец, - 2017.

9. Баева И.А. Психология безопасности как основа анализа экстремальной ситуации // Известия РГПУ им. А.И. Герцена. -2012. - № 145. 32

10. Бурмистрова Е.В. Психологическая помощь в кризисных ситуациях (предупреждение кризисных ситуаций в образовательной среде): метод. рекомендации для специалистов системы образования. - М.: МГППУ, 2006. - 359 с. 3. Казакова Е.И. Система комплексного сопровождения ребенка: от концепции к практике. - СПб., 1998. - 364 с. 4. Никольская И.М. Психологическая защита у детей / И.М. Никольская, Р.М. Грановская. - СПб.: Речь, 2000. - С. 175-177, 194-196, 201-203, 238-257.

11. Федеральный закон «0б основных гарантиях прав ребенка в Российской Федерации» от 24 июля 1998 года № 124-Ф3 (в ред. Федеральных законов от 20.07.2000 № 103-Ф3, от 22.08.2004 № 122-Ф3, от 21.12.2004 № 170-Ф3, от 26.06.2007 № 118-Ф3, от 30.06.2007 № 120-Ф3), гл. 1, ст. 1.

12. Куницына В.Н. Стиль общения и его формирование / - Л.: Ленингр. орг. 0-ва "Знание" РСФСР, 1985./Куницына Валентина Николаевна

13. Абдуллина М.А. Формирование культуры общения у старшеклассников в образовательном процессе: Дис. ... канд. пед. наук: 13.00.01: Уфа, 2001200 с. РГБ ОД, 61:02-13/427-6

14. Леонтьев А.А. Психология общения. - М.: Смысл, 1997. 